\title{
Shallow marine response to the Paleocene-Eocene Thermal Maximum in low-latitude Eastern Tethys
}

YING CUI $^{1}$, SHIJUN JIANG ${ }^{2}$, YASU WANG ${ }^{2}$, JINGXIN JIANG $^{3}$

${ }^{1}$ Department of Earth and Environmental Studies, Montclair State University, Montclair, NJ 07043

${ }^{2}$ Institute of Groundwater and Earth Sciences, Jinan University, Guangzhou 510632, China

${ }^{3}$ Southern Marine Science and Engineering Guangdong Laboratory (Zhuhai), Zhuhai 519082, China

${ }^{4}$ State Key Laboratory of Mineral Deposits Research, School of Earth Sciences and Engineering, Nanjing University, Nanjing, China

The Paleocene-Eocene Thermal Maximum (PETM) that occurred 56 million years ago represent one of the best ancient analogs that share many similarities with ongoing climate change. Although this event has been documented extensively in many regions across the globe, the low latitude Eastern Tethys remains enigmatic despite its importance in heat and moisture transport during the PETM, therefore limiting our understanding of the effect of warming and ocean acidification on shallow marine biota. Here we report a newly discovered shallow marine PETM section in Xinjiang Uygur Antonomous Region in Northwestern China. The shallow water depth is evidenced by the common abundance of several Micrantholithus species (calcareous nannofossil). Nannofossil biostratigraphy and stable carbon isotopes of marine carbonates suggest that the PETM is associated with the occurrence of Discoaster araneus and Rhomboaster in Zone NP10 and a -7\% carbon isotope excursion (CIE), and the pre-onset excursion (POE) is linked to Discoaster multiradiatus and Fasciculithus schaubii of Zone NP 9, and a $\sim-2 \%$ CIE. Malformed nannofossils at the shallow Eastern Tethys suggest shallow ocean acidification, likely driven by the large $\mathrm{CO}_{2}$ pulse associated with the North Atlantic Igneous Province (NAIP) during the PETM. Several carbon emission scenarios were simulated in an Earth system model of intermediate complexity to infer the role of NAIP in driving shallow marine acidification in the Eastern Tethys. 